\title{
Electrochemical Study of the Corrosion Behavior of Zinc Surface Treated with a New Organic Chelating Inhibitor
}

\author{
R. A. Prabhu, ${ }^{1}$ T. V. Venkatesha, ${ }^{2}$ and B. M. Praveen ${ }^{3}$ \\ ${ }^{1}$ Department of Chemistry, M.G.C. Arts, Commerce and G.H.D. Science College, Karnataka Siddapur 581 355, India \\ ${ }^{2}$ Department of P.G. Studies and Research in Chemistry, Kuvempu University, Karnataka Shankaraghatta 577451, India \\ ${ }^{3}$ Department of Chemistry, Srinivas School of Engineering, Mukka, Karnataka Mangalore 575 021, India
}

Correspondence should be addressed to T. V. Venkatesha, drtvvenkatesha@yahoo.co.uk

Received 22 June 2012; Accepted 2 August 2012

Academic Editors: M. Carboneras and T. Yue

Copyright (C) 2012 R. A. Prabhu et al. This is an open access article distributed under the Creative Commons Attribution License, which permits unrestricted use, distribution, and reproduction in any medium, provided the original work is properly cited.

\begin{abstract}
The effect of a new organic compound (N-[(1E)-(4 methoxy phenyl)methylene]hydrazinecarbothioamide), called ATSC, with chelating groups, on the corrosion behavior of zinc was investigated. Electrochemical study of the zinc specimens was carried out in aqueous electrolyte containing $0.2 \mathrm{M} \mathrm{Na}_{2} \mathrm{SO}_{4}$ and $0.2 \mathrm{M} \mathrm{NaCl}$ maintained at $\mathrm{pH} 5$ using galvanostatic polarization curves. The surface treatment of zinc was achieved by immersion in solutions of different concentrations of ATSC and for different immersion time and bath temperatures. The zinc metal treated with ATSC at 5\% has showed good corrosion resistance and maximum protection efficiency of about $84 \%$ at $300 \mathrm{~K}$. Moreover, the treatment induced a basic modification of the cathodic nature of zinc and controls the corrosion by decreasing the electron transfer rate. The corrosion protection could be explained by the formation of a protective organometallic layer on the zinc surface due to the chelation reaction between zinc and inhibitor molecules. Scanning electron microscopy (SEM) and Fourier transform infrared spectroscopy (FT-IR) were applied to study the protective layer.
\end{abstract}

\section{Introduction}

Zinc is one of the most important non-ferrous metals, which finds extensive use in metallic coatings. Zinc, like aluminium, is amphoteric in its behavior towards acids and alkalies. Zinc and zinc-coated products corrode rapidly in moist atmospheres forming white corrosion product-white rust. Thus it is necessary to protect it from corrosion in acid as well as in alkaline medium. This can be achieved by using special organic compounds. Various organic reagents have been used for inhibiting the corrosion process of zinc and galvanized steel in neutral, weak acid, and alkaline solutions. The dissolution behavior of zinc in acid and nearly neutral media is efficiently inhibited by compounds containing nitrogen and sulfur. Such organic compounds generally increase the hydrogen over voltage on corroding metal [1]. The studies pertaining to the effect of organic additives on corrosion rate of zinc in acid solutions have been the subject of interest for many investigators [2]. Several researchers have studied the effect of aldehydes and amines on corrosion of many metals in different corrosive environments [3-5]. Several pyrazole derivatives, substituted $\mathrm{N}$-aryl pyrroles, quinolines, bisaminotriazole and triazole derivatives, ethanolamine derivatives, aromatic hydroxyl compounds have been acted in the literature as corrosion inhibitors for zinc in different media. [6-11]. It was established that these compounds form protective layer or film on the metallic surface. The role of this film is to isolate the corroding metal from the corrosive media.

The Schiff's bases are also used as effective corrosion inhibitors in different media [12]. Many Schiff's bases act as anodic or cathodic or mixed inhibitors. The mechanism of action of these bases is similar to organic compounds containing $\mathrm{N}, \mathrm{S}$, and $\mathrm{O}$ elements in their functional groups. The Schiff's bases of ortho-, meta-, and para-aminophenol with $\mathrm{N}$-salicylaldehyde have been reported as corrosion inhibitors for zinc in sulfuric acid medium [13]. Most of the compounds form either complex or interact with cathodic or anodic sites of metal and there by reduces the rate of electrochemical reactions. Few Schiff's bases also form zinc metal complexes [14]. 
The literature on corrosion inhibitors revealed that majority of compounds control the corrosion through the formation of their complex with metal ion. Taking this idea, to control corrosion, many investigators tried to modify the surface of metals by treating them with solutions of complexing agents. Many reports in the literature are connected to modify the surface of metal by complexing it with organic compounds [15]. The complex forming ability of organic compounds with zinc was the main criteria for selecting them as surface modifiers [16, 17]. In this modification process, the metal is immersed in the solutions of complexing agents for a definite period of time. During the interaction a few micron thickness of metal surface is converted into metal chelates or metal complexes. These complexes form a thin film on metal surface which acts as a barrier between metal and corrosive medium.

In the present work, a Schiff's base was prepared and used for the treatment of zinc surface. The prepared molecule contains electroactive covalent $(>\mathrm{NH})$ and coordinating $(>\mathrm{C}=\mathrm{N}-$ and $>\mathrm{C}=\mathrm{S}$ ) groups and aromatic ring. This facilitates delocalization of the $\pi$-electrons and enhances the complex formation ability with the surface metal atoms. The metal was treated by immersing in the treatment solution of known concentrations for different time intervals and temperatures. The modified metal surface was subjected to the study to establish its performance against corrosion. The protective layers formed on the zinc surface after immersion in the treatment solutions were analyzed by SEM and IR studies.

\section{Experimental}

A condensation product between anisaldehyde and thiosemicarbazide was prepared in the laboratory by adopting standard procedure [18]. A mixture of $\mathrm{p}$-anisaldehyde (0.005 mol) and thiosemicarbazide $(0.005 \mathrm{~mol})$ in $20 \mathrm{~mL}$ ethanol and acetic acid mixture was stirred for $4 \mathrm{hr}$ at room temperature. After the reaction, the separated solid was filtered out, dried, and crystallized from ethanol and dioxin mixture. The prepared Schiff's base N-[(1E)-(4-methoxy phenyl) methylene]hydrazinecarbothioamide (ATSC) was subjected to IR studies and the spectral data indicated the presence of $-\mathrm{NH},-\mathrm{NH} 2,>\mathrm{C}=\mathrm{S}$, and $>\mathrm{C}=\mathrm{N}-$ groups. The structure of ATSC is shown in Figure 1.

The $1 \%, 3 \%$, and $5 \%$ solutions of ATSC were prepared in ethanol. The $1 \mathrm{~mol} \mathrm{dm}^{-3} \mathrm{HCl}$ was prepared by using A.R. grade $\mathrm{HCl}$ and triple-distilled water. All experimental observations were performed in aerated and stirred solutions.

Zinc specimens having composition $\mathrm{Cu} 0.17 \%$, Ti 0.075, $\mathrm{Al} \mathrm{0.005 \% ,} \mathrm{Pb-Cd} \mathrm{0.003,} \mathrm{Fe} \mathrm{0.002 \% ,} \mathrm{Sn} \mathrm{0.0015,} \mathrm{Mg} \mathrm{0.005,}$ and rest being zinc were used. The specimens of dimension $5 \mathrm{~cm} \times 1 \mathrm{~cm} \times 0.1 \mathrm{~cm}$ with an exposed area of $1 \mathrm{~cm}^{2}$ (other parts are covered with araldite resin) were used for polarization measurement. The samples were mechanically polished using emery papers of grade no. 400, 600, 800, and 1000 and were rinsed with ethanol and triple-distilled water and dried in air. A cell containing three compartments for electrodes was used. The working zinc electrode embedded in araldite with exposed area $1 \mathrm{sq} \mathrm{cm}$. was dipped in the test

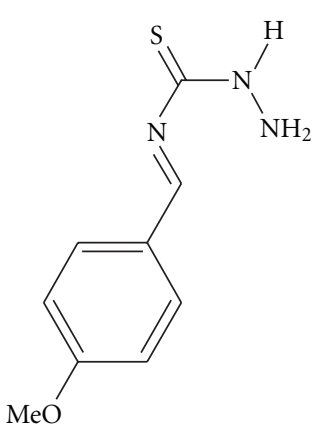

N-[(1E)-(4-methoxyphenyl)methylene]hydrazinecarbothioamide

Figure 1: Structure of ATSC.

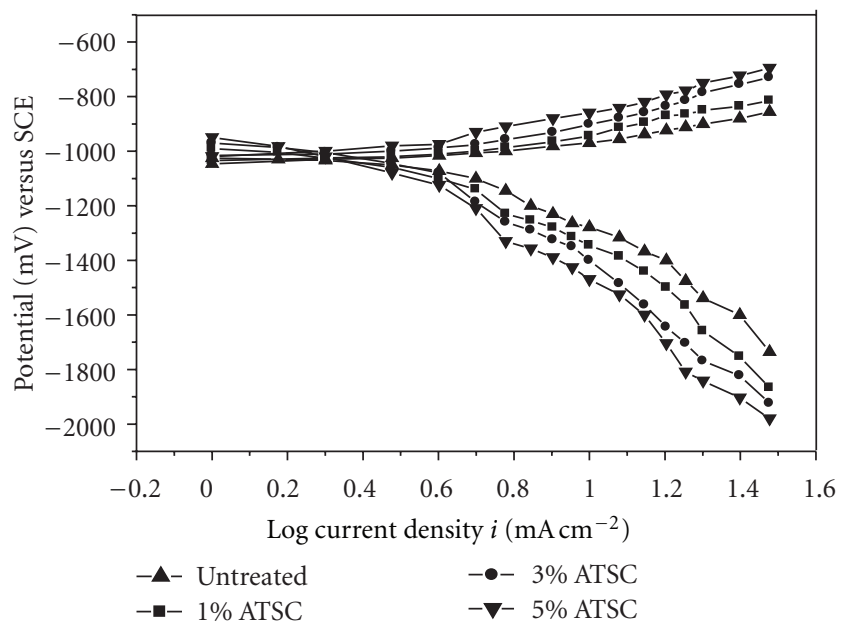

FIgURE 2: Polarisation curves for untreated and treated zinc in different concentrations of ATSC.

solution. A saturated calomel electrode, (SCE) and a platinum electrode were used as the reference and the counter electrodes respectively. All potentials were measured verses SCE. The potentials were scanned primarily in the cathodic direction from the corrosion potential and subsequently in the anodic direction.

The zinc was treated by immersing in the treatment solution of known concentrations of ATSC for different time intervals and also at different temperatures. The performance of treated zinc was examined by adopting galvanostatic polarization studies using a electrolyte containing $0.2 \mathrm{M}$ $\mathrm{Na}_{2} \mathrm{SO}_{4}$ and $0.2 \mathrm{M} \mathrm{NaCl}$. The $\mathrm{pH}$ of the electrolyte was maintained at 5.0 ( $\mathrm{pH}$ was adjusted by using $\mathrm{HCl}$ or $\mathrm{NaOH}$ ).

\section{Results and Discussion}

\subsection{Galvanostatic Polarization Studies}

3.1.1. Effect of Concentration. The zinc specimens were immersed in the treatment solution of different concentrations of ATSC (1\%, 3\%, and 5\%) separately for 4 hours. The specimens so treated were subjected to polarization study. Galvanostatic polarization measurements were conducted on treated zinc specimen to determine the corrosion potential, corrosion current, and percentage protection efficiency in 
TABLE 1: Corrosion parameters in $0.2 \mathrm{M} \mathrm{Na}_{2} \mathrm{SO}_{4}+0.2 \mathrm{M} \mathrm{NaCl}$ for zinc treated with different concentrations of ATSC.

\begin{tabular}{lcccr}
\hline $\begin{array}{l}\text { Concentration } \\
(\%)\end{array}$ & $\begin{array}{c}-E_{\text {corr }} \\
(\mathrm{mV})\end{array}$ & $\begin{array}{c}-b_{c} \\
(\mathrm{mV} / \mathrm{dec})\end{array}$ & $\begin{array}{c}b_{a} \\
(\mathrm{mV} / \mathrm{dec})\end{array}$ & $\begin{array}{c}I_{\text {corr }} \\
\left(\mathrm{mA} / \mathrm{cm}^{-2}\right)\end{array}$ \\
\hline Blank (0.2 M HCl) & 1027 & 180 & 105 & 0.67 \\
$1 \%$ & 1022 & 240 & 110 & 0.26 \\
$3 \%$ & 1016 & 255 & 112 & 0.17 \\
$5 \%$ & 1005 & 264 & 114 & 0.11 \\
\hline
\end{tabular}

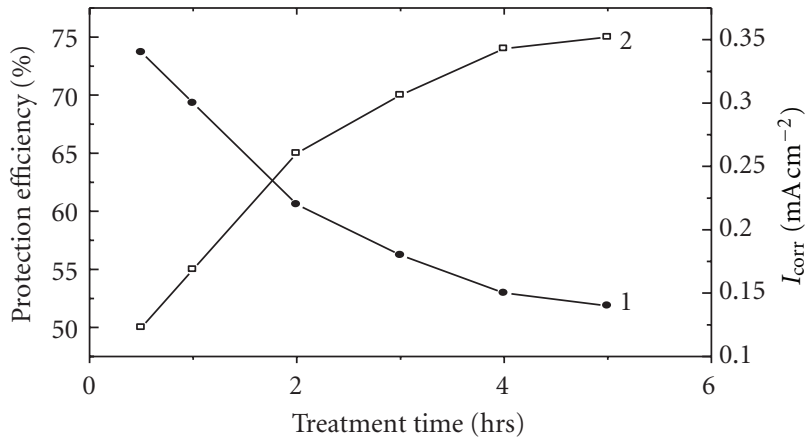

FIGURE 3: $I_{\text {corr }}$ and percentage inhibition efficiency for zinc samples treated in 3\% ATSC solution at different treatment times at $300 \mathrm{~K}$. (1) $I_{\text {corr }}$ and (2) protection efficiency.

corrosion solution containing $\mathrm{Na}_{2} \mathrm{SO}_{4}$ and $\mathrm{NaCl}$ salts. The polarization curves of untreated and treated zinc samples are shown in Figure 2.

The corrosion current densities were determined by extrapolating the cathodic and anodic Tafel lines to intersect. The results showed that the protection efficiency increased with concentration of ATSC in treatment solution for the same immersion period. The values of $E_{\text {corr }}$ got shifted towards noble direction and the values of $I_{\text {corr }}$ were found to decrease. The cathodic curves gradually moved towards lower current density regions as the concentration of compounds increased as where the anodic curves did not show any appreciable shift. The highest protection efficiency against corrosion of zinc was observed for the sample treated in 5\% ATSC solution. This effect could result from the presence of an organometallic protective film on the electrode surface and decreasing the effective electron transfer rate at the interface.

The corrosion current densities were determined by extrapolating the cathodic and anodic Tafel lines to intersect. The results showed that the protection efficiency increased with concentration of ATSC in treatment solution for the same immersion period. The values of $E_{\text {corr }}$ got shifted towards noble direction and the values of $I_{\text {corr }}$ were found to decrease. The cathodic curves gradually moved towards lower current density regions as the concentration of compounds increased, as where the anodic curves did not show any appreciable shift. The highest protection efficiency against corrosion of zinc was observed for the sample treated in 5\% ATSC solution. This effect could result from the presence of an organometallic protective film on the electrode surface and decreasing the effective electron transfer rate at the interface.
Table 1 gives the values of corrosion current $\left(I_{\text {corr }}\right)$, corrosion potential $\left(E_{\text {corr }}\right)$, anodic and cathodic Tafel slopes $\left(b_{a}\right.$ and $\left.b_{c}\right)$, and protection efficiency (PI\%) of ATSC. The corrosion potential $\left(E_{\text {corr }}\right)$ were found to be $-1010 \mathrm{mV}$. The protection efficiency $\mathrm{PI} \%$ was calculated using the relation [19]

$$
\mathrm{PI} \%=\frac{\left(I_{\text {corr }}\right)_{2}-\left(I_{\text {corr }}\right)_{1}}{\left(I_{\text {corr }}\right)_{2}} \times 100,
$$

where $\left(I_{\text {corr }}\right)_{1}$ and $\left(I_{\text {corr }}\right)_{2}$ are the corrosion current densities in the presence and absence of the inhibitor, respectively.

The magnitude of Tafel slopes indicated that the corrosion protection efficiency was increased for the samples treated separately with solutions of higher concentrations of ATSC. The $I_{\text {corr }}$ values decreased significantly with increase in the concentrations of the ATSC. This indicated that the compound acts like a good surface modifiers for zinc.

The higher corrosion protection efficiency may be attributed to the presence of delocalized $\pi$ electrons and presence of lone pair of electrons on sulfur and nitrogen atoms of $>\mathrm{C}=\mathrm{S}-$ and $>\mathrm{C}=\mathrm{N}-$ groups in ATSC molecule. Further the presence of activating group methoxy $\left(-\mathrm{OCH}_{3}\right)$ increases the electron density on the nitrogen atom. This leads to the effective surface modification of zinc.

3.1.2. Effect of Treatment Time. Figure 3 shows the influence of immersion time on protection efficiency. The protection efficiency was gradually increased with increase in immersion time up to $5 \mathrm{hrs}$ and then almost constant for treated samples in 3\% ATSC solution. The increase in the protection efficiency values can be attributed to the progressive formation of a protective organometallic film on the electrode surface. The inhibition efficiency for treated sample reached to a maximum value of $75 \%$.

3.1.3. Effect of Temperature. Zinc specimens were treated in 3\% ATSC solution for $4 \mathrm{hrs}$ and subjected to corrosion study at different temperatures. The effect of temperature on the corrosion behavior of treated zinc is shown in Figure 4 . The protection efficiency was found to decrease to some extent with increase in temperature of the electrolyte. The temperature around $306 \mathrm{~K}$ was the optimum temperature for the formation of organometallic layer on zinc surface.

\subsection{Zinc Surface Studies}

3.2.1. Scanning Electron Microscopic Studies (SEM). SEM study was performed to investigate the nature of protective layer generated during treatment on the zinc surface. 


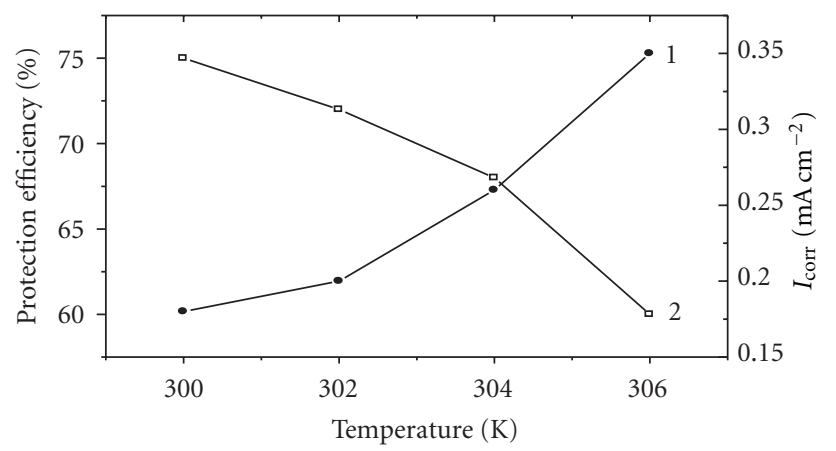

FIGURE 4: Temperature effect on the $I_{\text {corr }}$ and protection efficiency of the treated zinc in 3\% ATSC for 4 hrs. (1) $I_{\text {corr }}$ and (2) protection efficiency.

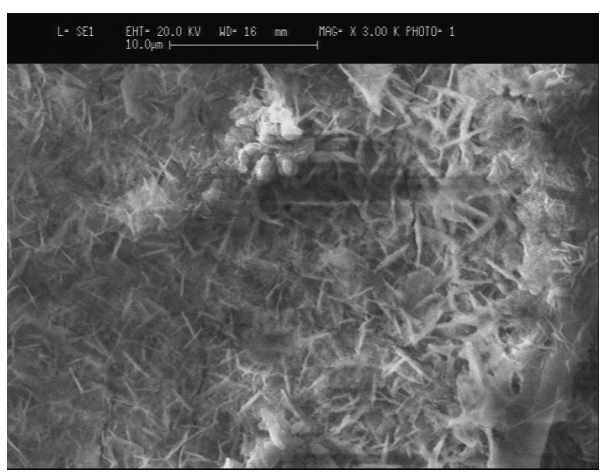

(a)

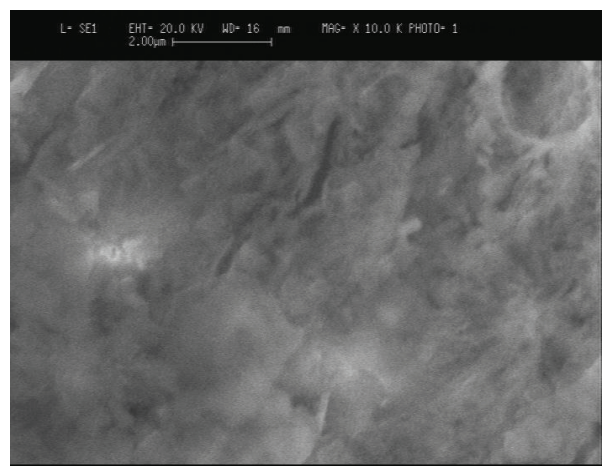

(b)

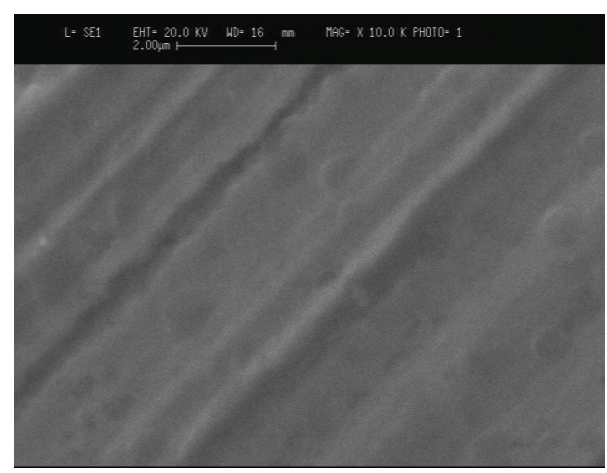

(c)

Figure 5: (a) zinc in $0.2 \mathrm{M} \mathrm{Na}_{2} \mathrm{SO}_{4}+0.2 \mathrm{M} \mathrm{NaCl}$, (b) treated Zinc with ATSC, and (c) untreated Zinc.

Figure 5(a) shows the photomicrograph of the zinc surface taken after 20 minutes of anodic polarization ( $10 \mathrm{~mA}$ applied current) in $0.2 \mathrm{M} \mathrm{Na}_{2} \mathrm{SO}_{4}+0.2 \mathrm{M} \mathrm{NaCl}$ solution at $300 \mathrm{~K}$. The surface contains small cavities which are distributed over the entire surface and a needle like deposits (corrosion products) are observed. In the case of treated sample taken after 20 minutes of anodic polarization (10 mA applied current) needle type of deposits were not observed (Figure 5(b)). The surface shows only a few pits covered with white corrosion products. Figure 5(c) showed a passive film which was not subjected to the dissolution process.

3.2.2. Fourier Transform Infrared Spectroscopic Studies (FTIR). The FTIR spectrum was taken to confirm the formation of protective layer on the zinc surface. Figure 6(a) shows the IR spectrum of pure ATSC molecule. There are a number of different peaks of variable intensity arising from different functional groups. The characteristic peaks at 3289 and $3151 \mathrm{~cm}^{-1}$ were attributed to the stretching vibrations of the $-\mathrm{N}-\mathrm{H}$ bond of the amino group. Similarly the peaks at $1593,1536,1511 \mathrm{~cm}^{-1}$ and $1245,1173 \mathrm{~cm}^{-1}$ were attributed to the stretching vibrations of the $\mathrm{C}=\mathrm{N}$ bond of the imino group and $\mathrm{C}=\mathrm{S}$ bond, respectively. The IR spectrum of zinc specimen treated with the ATSC solution (Figure 6(b)) shows several modifications in these three domains. These peaks do not appear in the IR spectrum of the scraped layer of the treated zinc in 5\% ATSC solution. The disappearance of these bands indicated the interaction of nitrogen and sulfur atoms of the ATSC molecule and the zinc [20]. 


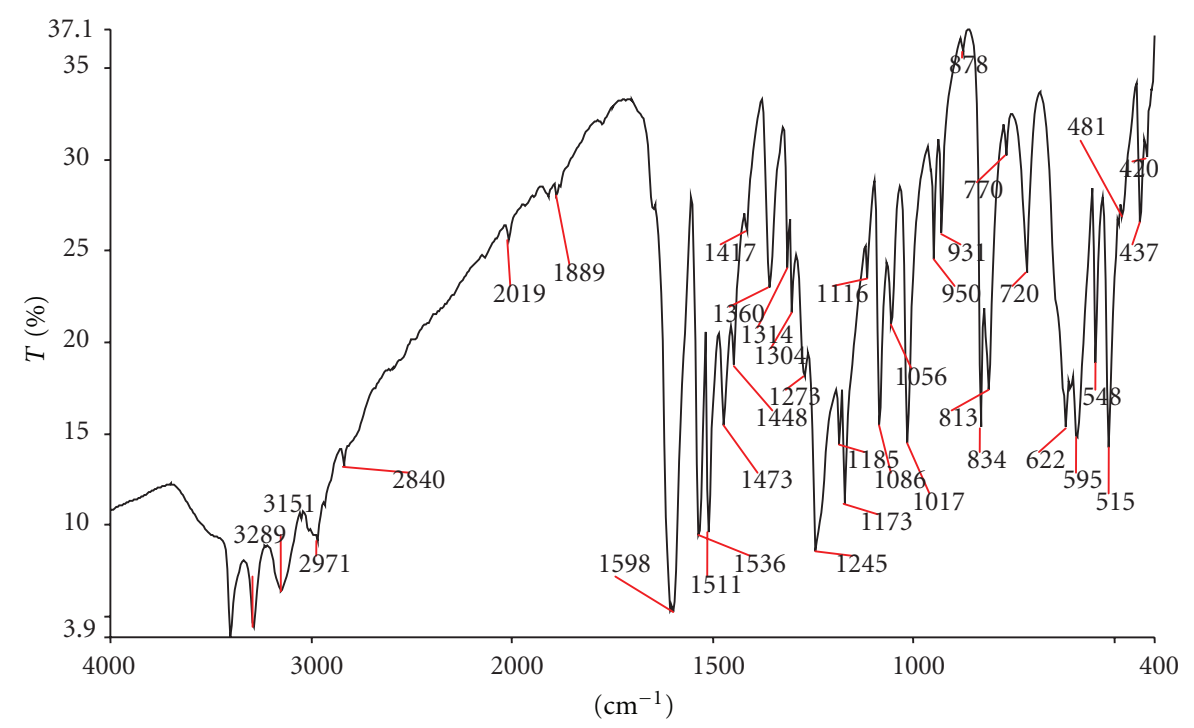

(a)

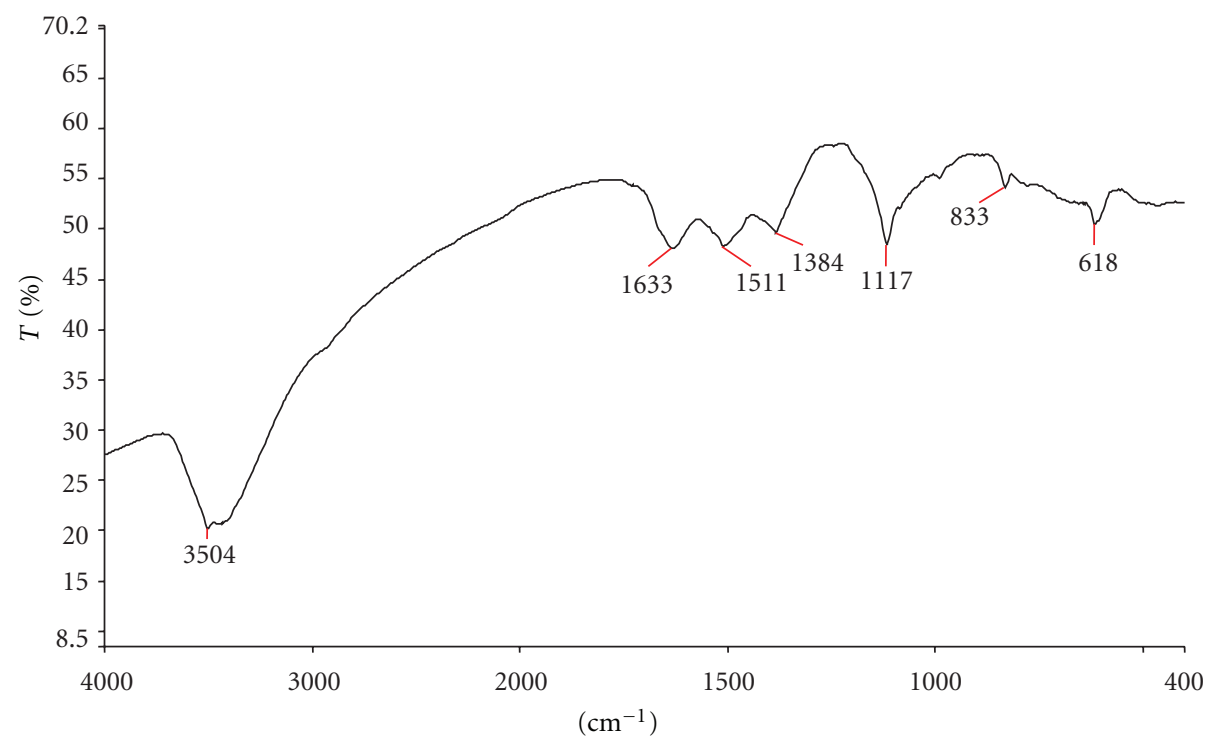

(b)

FIGURE 6: (a) FTIR spectrum of ATSC (pure compound), (b) FTIR spectrum of ATSC (scrap compound).

\section{Discussion}

The cathodic polarization curves exhibited two separated diffusion plateaus which were due to the electrochemical reduction of dissolved oxygen:

$$
\mathrm{O}_{2}+4 \mathrm{e}^{-}+2 \mathrm{H}_{2} \mathrm{O} \longrightarrow 4 \mathrm{OH}^{-}
$$

The oxygen reduction mechanism becomes complex in such systems where mass transport takes place in the solution phase as well as on the metal surface. The oxygen reduction reaction occurred in the vicinity of the corrosion potential through a more or less porous layer (first plateau) [21]. This layer consists of corrosion products formed during a short preliminary hold time at the free corrosion potential. At higher cathodic over potentials (second plateau) the whole surface became active; hence the oxygen reduction reaction took place at higher rate at the metal layer-solution interface. Obviously the current density increased at higher cathodic over potentials. The corrosion process in the case of untreated zinc in aerated sulphate solution was found to be cathodically controlled [22]. The corrosion current density was obtained from the cathodic diffusion current at the point of first plateau. The corrosion current density and corrosion potential were found to be $16 \mathrm{~mA} \mathrm{~cm}^{-2}$ and $-1375 \mathrm{mV}$, respectively.

The higher corrosion resistance exhibited by the zinc samples, treated in 5\% ATSC solution indicated that the surface exposed to corrosive medium was less active due to the improvement of the surface coverage by ATSC molecules during the treatment in solution containing higher concentration. The treatment of zinc with ATSC solution induced a basic modification in the cathodic behavior of zinc metal. 
With increase in concentration of ATSC, the cathodic curve became linear and shifted towards lower current densities. This effect could be attributed to the formation of an organometallic protective film on the electrode surface and subsequent decrease in the rate of electron transfer reaction at the surface. Thus the cathodic reaction becomes largely under charge transfer control.

The inhibition efficiency increased with immersion time giving evidence of the progressive formation of a protective film on the electrode surface. After five hours, inhibition efficiency was stabilized and reached $75 \%$.

The electrochemical behavior of the treated samples depends on the temperature. The protection efficiency decreased slightly with the increase of temperature showing predominance of dissolution of zinc and evolution of hydrogen.

The results of FTIR revealed the possibility of bond formation between organic compound and zinc.

\section{Conclusions}

Electrochemical study showed that the zinc metal treated with ATSC has good corrosion resistance in aqueous chloride-sulphate solution. The observed protection against corrosion was particularly affected by the concentration of the Schiff's base, treatment time, concentration of aggressive medium, and temperature. Maximum protection efficiency about $84 \%$ is obtained in the $5 \%$ ATSC solutions at $300 \mathrm{~K}$. The treatment induced a basic modification in the cathodic behavior of zinc and controls the corrosion by decreasing the electron transfer rate. The SEM images showed the formation of a passive film on the treated zinc. The spectral studies confirmed the formation of a stable organometallic film and it is strongly attached to the zinc surface through the establishment of chemical interaction through electroactive $>\mathrm{C}=\mathrm{N}-,>\mathrm{C}=\mathrm{S}-$ groups with the zinc surface. Therefore, the prepared ATSC compound modifies the zinc metal surface and provides good protection to zinc against corrosion in aqueous aggressive medium.

\section{Acknowledgments}

The authors thank Mr. R. G. Kalkhambkar, M.Sc., and Dr. (Smt.)G. M. Kulakarni. Department of Chemistry, Karnatak Science College, Dharwad, for their cooperation during this work.

\section{References}

[1] B. R. W. Hinton and L. Wilson, "The corrosion inhibition of zinc with cerous chloride," Corrosion Science, vol. 29, no. 8, pp. 967-975, 1989.

[2] S. K. Rajappa, T. V. Venkatesha, and B. M. Praveen, "Chemical treatment of zinc surface and its corrosion inhibition studies," Bulletin of Material Science, vol. 31, no. 1, pp. 37-41, 2008.

[3] M. S. Abdel-All, Z. A. Ahmed, and M. S. Hassan, "Inhibiting and accelerating effects of some quinolines on the corrosion of zinc and some binary zinc alloys in $\mathrm{HCl}$ solution," Journal of Applied Electrochemistry, vol. 22, no. 11, pp. 1104-1109, 1992.
[4] R. T. Vashi and V. A. Champaneri, "Nitro anilines as corrosion inhibitors for zinc in sulfamic acid," Bulletin of Electrochemistry, vol. 13, no. 8-9, pp. 353-357, 1997.

[5] T. Du, J. Chen, and D. Cao, "N,N-Dipropynoxy methyl amine trimethyl phosphonate as corrosion inhibitor for iron in sulfuric acid," Journal of Materials Science, vol. 36, pp. 39033907, 2001.

[6] E. Stupnisek-Lisac, S. Podbrscek, and T. Soric, "Non-toxic organic zinc corrosion inhibitors in hydrochloric acid," Journal of Applied Electrochemistry, vol. 24, pp. 779-784, 1994.

[7] M. S. Abdel-All, Z. A. Ahmed, and M. S. Hassan, "Inhibiting and accelerating effects of some quinolines on the corrosion of zinc and some binary zinc alloys in $\mathrm{HCl}$ solution," Journal of Applied Electrochemistry, vol. 22, pp. 1104-1109, 1992.

[8] K. Wippermann, J. W. Schaltze, R. Kessel, and T. Penninger, "The inhibition of zinc corrosion by bisaminotriazole and other triazole derivatives," Corrosion Science, vol. 32, pp. 205223, 1991.

[9] H. M. Bhajiwala and R. T. Vashi, "Ethanolamine, diethanolamine and triethanolamine as corrosion inhibitors for zinc in binary acid mixture $\left[\mathrm{HNO}_{3}+\mathrm{H}_{3} \mathrm{PO}_{4}\right]$," Bulletin of Electrochemistry, vol. 17, no. 10, pp. 441-448, 2001.

[10] B. Muller and I. Forster, "Inhibition of zinc pigments in aqueous alkaline media by aromatic hydroxy compounds," Corrosion Science, vol. 52, no. 10, pp. 786-789, 1996.

[11] S. Manov, F. Noli, A. M. Lamazouere, and L. Aries, "Surface treatment for zinc corrosion protection by a new organic chelating reagent," Journal of Applied Electrochemistry, vol. 29, no. 8, pp. 995-1003, 1999.

[12] Y. K. Agarwal, J. D. Talati, M. D. Shah, M. N. Desai, and N. K. Shah, "Schiff bases of ethylenediamine as corrosion inhibitors of zinc in sulphuric acid," Corrosion Science, vol. 46, no. 3, pp. 633-651, 2004.

[13] J. D. Talati, M. N. Desai, and N. K. Shah, "Ortho-, meta-, and para-aminophenol-N-salicylidenes as corrosion inhibitors of zinc in sulfuric acid," Anti-Corrosion Methods and Materials, vol. 52, no. 2, pp. 108-117, 2005.

[14] S. K. Rajappa and T. V. Venkatesha, "Inhibition studies of a few organic compounds and their condensation products on the corrosion of zinc in hydrochloric acid medium," Turkish Journal of Chemistry, vol. 27, pp. 189-196, 2003.

[15] S. Manov, F. Noli, A. M. Lamazouere, and L. Aries, "Surface treatment for zinc corrosion protection by a new organic chelating reagent," Journal of Applied Electrochemistry, vol. 29, no. 8, pp. 995-1003, 1999.

[16] M. Ihara, H. Nishihara, and K. Aramaki, "Mechanism of corrosion inhibition with bismuth compounds for iron, nickel and zinc in acid solutions," Denki Kagaku, vol. 60, pp. 500507, 1992.

[17] B. Muller and G. Imblo, "Heterocycles as corrosion inhibitors for zinc pigments in aqueous alkaline media," Corrosion Science, vol. 38, pp. 293-300, 1996.

[18] R. T. Morris and R. N. Boyd, Organic Chemistry, Pretice-Hall of India Pvt, 1973.

[19] C. Emregul, A. Abdulkadir Akay, and O. Atakol, "The corrosion inhibition of steel with Schiff base compounds in $2 \mathrm{M} \mathrm{HCl}$," Materials Chemistry and Physics, vol. 93, no. 2-3, pp. 325-329, 2005.

[20] S. Manov, F. Noli, A. M. Lamazouere, and L. Aries, "Surface treatment for zinc corrosion protection by a new organic chelating reagent," Journal of Applied Electrochemistry, vol. 29, no. 8, pp. 995-1003, 1999.

[21] C. Deslouis, M. Duprat, and C. Tournillon, "The cathodic mass transport process during zinc corrosion in neutral 
aerated sodium sulphate solutions," Journal of Electroanalytical Chemistry and Interfacial Electrochemistry, vol. 181, no. 1-2, pp. 119-136, 1984.

[22] C. Fiaud, S. Bensarsa, I. D. des Aulnois et al., "Inhibiting properties of phosphines against zinc corrosion in acidic media," British Corrosion Journal, vol. 22, pp. 109-114, 1987. 

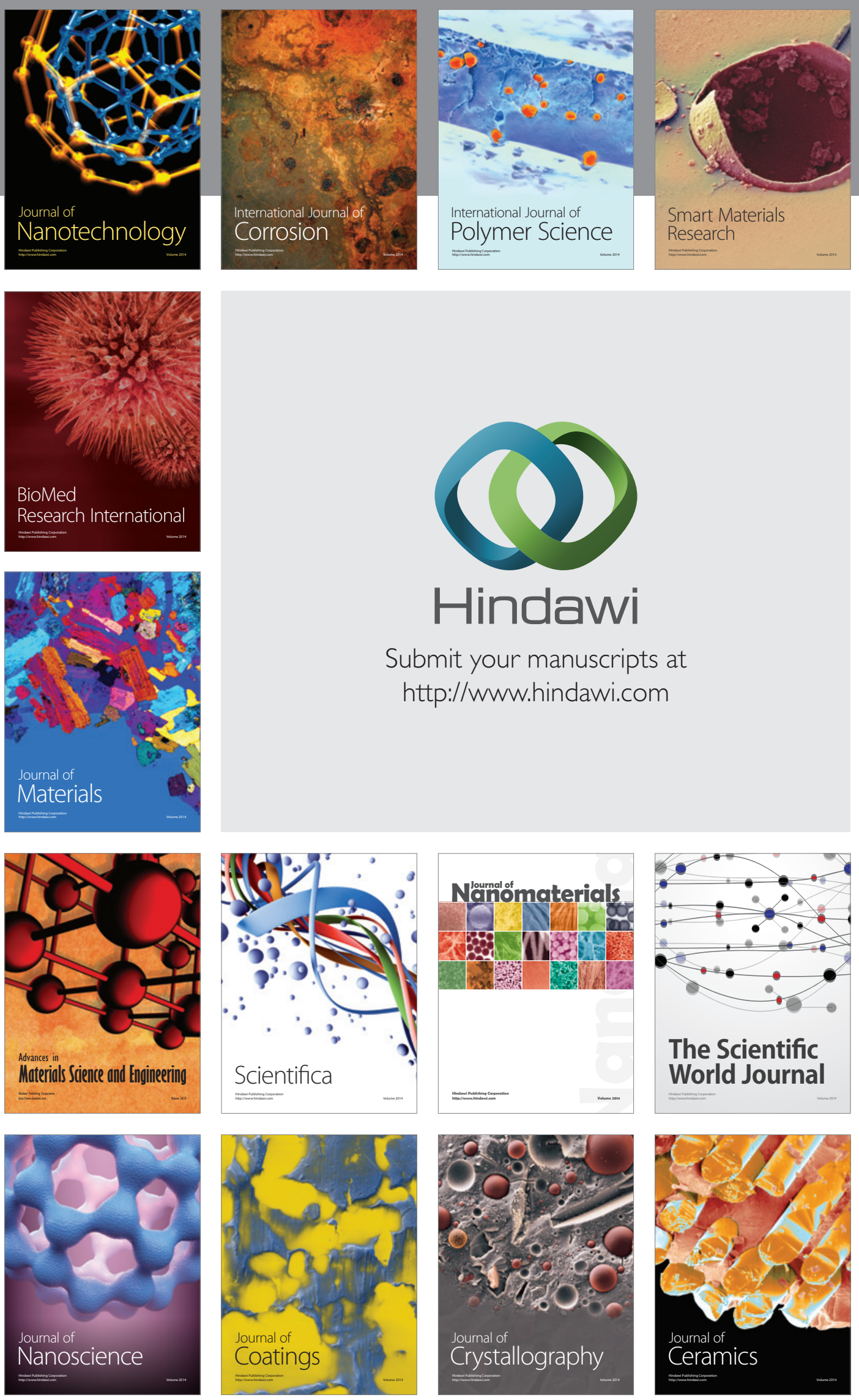

The Scientific World Journal

Submit your manuscripts at

http://www.hindawi.com

\section{World Journal}

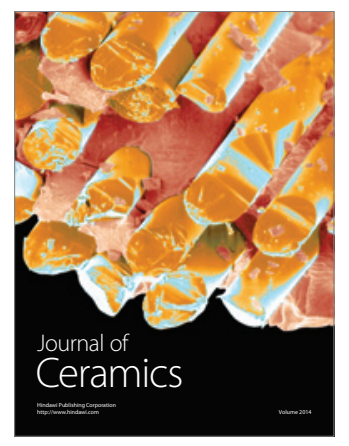

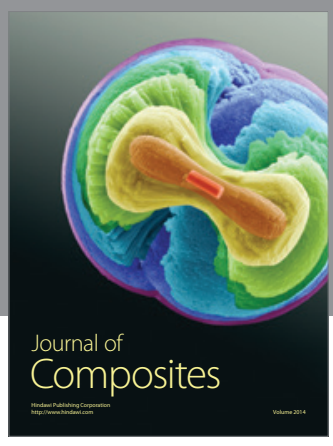
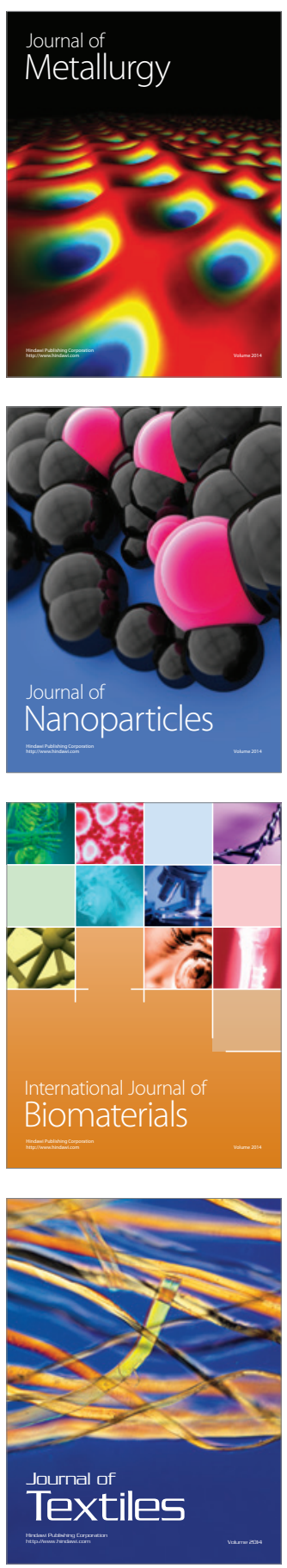